\title{
Effects of oxygenate concentration on species mole fractions in premixed $n$-heptane flames
}

\author{
Fikret Inal $^{\mathrm{a}, *}$, Selim M. Senkan ${ }^{\mathrm{b}}$ \\ ${ }^{a}$ Department of Chemical Engineering, Izmir Institute of Technology, Gulbahce-Urla, 35430 Izmir, Turkey \\ ${ }^{\mathrm{b}}$ Department of Chemical Engineering, University of California, Los Angeles, CA 90095, USA
}

Received 9 June 2004; received in revised form 12 October 2004; accepted 13 October 2004

Available online 19 November 2004

\begin{abstract}
Atmospheric pressure, laminar, premixed, fuel-rich flames of $n$-heptane/oxygen/argon and $n$-heptane/oxygenate/oxygen/argon were studied at an equivalence ratio of 1.97 to determine the effects of oxygenate concentration on species mole fractions. The oxygen weight percents in $n$-heptane/oxygenate mixtures were 2.7 and 3.4. Three different fuel oxygenates (i.e. MTBE, methanol, and ethanol) were tested. A heated quartz micro-probe coupled to an on-line gas chromatography/mass spectrometry has been used to establish the identities and absolute concentrations of stable major, minor, and trace species by the direct analysis of samples, withdrawn from the flames. The oxygenate addition has increased the maximum flame temperatures and reduced the mole fractions of CO, low-molecular-weight hydrocarbons, aromatics, and polycyclic aromatic hydrocarbons. The reduction in mole fractions of aromatic and polycyclic aromatic hydrocarbon species by an increase in oxygenate concentration was more significant.
\end{abstract}

(C) 2004 Elsevier Ltd. All rights reserved.

Keywords: Oxygenate; Premixed flame; $n$-Heptane

\section{Introduction}

Most of the world energy consumption is through the combustion of fossil fuels. Oil accounts for about $40 \%$ of world commercial energy supplies [1]. Since the significant amount of oil is used as transportation fuel, mobile source emissions are the major contributors to urban air pollution. One of the approaches to achieve the reduction in these emissions is the improvement in motor vehicle fuel properties. Fuel oxygenates were first used as an octane replacement for lead since lead inactivates the exhaust catalyst. They are also known for their ability to reduce exhaust $\mathrm{CO}$ emissions by leaning the fuel-air mixture. Several oxygen-containing compounds (i.e. oxygenates) such as alcohols (e.g. methanol, ethanol, and tertiary butyl alcohol) and ethers (e.g. methyl tertiary-butyl ether (MTBE), ethyl tertiary-butyl ether (ETBE), and tertiary amyl methyl ether (TAME)) were considered as possible

\footnotetext{
* Corresponding author. Tel.: +90 232750 6282; fax: +90 232750 6196.

E-mail address: fikretinal@iyte.edu.tr (F. Inal).
}

fuel oxygenates. MTBE and ethanol are the most common oxygenates currently used in gasoline.

$n$-Heptane is a component of commercial gasoline and one of the primary reference fuels for the determination of gasoline octane number which rates fuel's tendency to knock in an engine under standardized conditions. The oxidation of $n$-heptane has been studied using several experimental techniques, including shock tubes $[2,3]$, jet stirred reactors [4,5], premixed [6-9], and diffusion flames $[10,11]$.

Polycyclic aromatic hydrocarbons (PAH) and soot formations in a premixed $n$-heptane flame have been investigated by Westmoreland et al. [6] at an equivalence ratio of 2.05. The most abundant PAH compound reported was acenaphthylene. Peterca and Marconi [11] have also reported PAH species in laminar diffusion flames of $n$-heptane. Acenaphthylene and naphthalene were the most abundant PAH, a result that is in agreement with premixed flame measurements [6].

Temperature and species (stable and free radicals) mole fraction profiles in laminar, premixed $n$-heptane/oxygen/ argon flames at low pressure $(6.0 \mathrm{kPa})$ have been obtained 
by Doute et al. [7]. Atmospheric pressure, premixed, flat flames of $n$-heptane were investigated using unheated microprobe sampling and GC/MS both by Bakali et al. [8] and Ingemarsson et al. [9] at equivalence ratios of 1.9 and 1.0, respectively. Their studies were limited to low-molecularweight species only. Recently, we [12] have investigated the micro-structure of laminar, premixed, atmospheric pressure, fuel-rich flames of $n$-heptane/oxygen/argon at equivalence ratios of 1.97 and 2.10. Stable major, minor and trace species mole fraction profiles were obtained by direct analysis of the flame samples. Temperature and soot measurement results were also reported in this study.

Levinson [13] has investigated the effects of additives on ignition delay time of $n$-heptane in shock tube experiments. The additives used were ethylene, acetylene, 1-butene, toluene, methane, tetraethyl lead, ethane, 2-iodoprapane, di$t$-butylperoxide, acetaldehyde, carbon monoxide, and hydrogen. The ignition delays were lengthened by addition of a number of hydrocarbons, including increased heptane concentration. Ethane and acetylene were the exceptions.

Dagaut et al. [14] have investigated the oxidation of $n$-heptane in the presence of MTBE and ETBE in a high pressure jet-stirred reactor $(T=570-1170 \mathrm{~K}, P=10 \mathrm{~atm}$, and equivalence ratio $=1.0$ ). Oxidation rate of $n$-heptane was reduced by the addition of ethers below $800 \mathrm{~K}$. However, no significant effect on the oxidation rate was reported for the temperatures above $800 \mathrm{~K}$.

Recently, we [15] have studied the effects of three fuel oxygenates (methanol, ethanol, and MTBE) on the formation of PAH and soot in laminar, premixed, atmospheric pressure, fuel-rich flames of $n$-heptane at an equivalence ratio of 2.10. All the oxygenate additives reduced the mole fractions of aromatic and PAH species, as well as soot formation. The reduction in soot formation was comparable for different oxygenates.

Emissions from two-stroke [16,17] and four-stroke engines [18-23] with oxygenated fuels have been studied extensively in the literature. The effects of blending unleaded gasoline with different proportions of MTBE $(10,15$, and $20 \mathrm{vol} \%)$ on exhaust carbon monoxide, carbon dioxide, and hydrocarbon emissions from a fixed compression ratio SI engine were studied by Osman et al. [18]. The lowest carbon monoxide and hydrocarbon emissions were obtained with $20 \mathrm{vol} \%$ MTBE blend. In contrast, Zervas et al. [23] have reported that the effects of MTBE concentration in fuel blends on the exhaust emissions of regulated pollutants $\left(\mathrm{CO}, \mathrm{HC}\right.$, and $\left.\mathrm{NO}_{x}\right)$ from $\mathrm{CFR}$ spark ignition engine mostly depend on the engine operating conditions. For example, the addition of MTBE at 5 and $20 \mathrm{vol} \%$ has slightly decreased the emission of $\mathrm{CO}$ at airfuel ratio of 1.0. However, this decrease was more significant in the case of lean conditions, reaching $30 \%$ for both 5 and $20 \mathrm{vol} \%$ MTBE blends. Exhaust CO emissions remained unchanged by the addition of MTBE at rich conditions. Cadle et al. [20] have investigated the effects of oxygenated fuel (containing ethanol) on
Table 1

Experimental conditions studied at an equivalence ratio of 1.97

\begin{tabular}{lcc}
\hline & Flame-A & Flame-B \\
\hline$n$-Heptane/MTBE flame & & \\
$n$-Heptane (mol\%) & 4.55 & 4.36 \\
Argon (mol\%) & 65.26 & 65.39 \\
$\begin{array}{l}\text { Oxygen in } n \text {-heptane/oxygenate blend } \\
\text { (wt\%) }\end{array}$ & 2.7 & 3.4 \\
$n$-Heptane/methanol flame & & \\
$n$-Heptane (mol\%) & 5.04 & 4.97 \\
Argon (mol\%) & 64.96 & 65.01 \\
Oxygen in $n$-heptane/oxygenate blend & 2.7 & 3.4 \\
(wt\%) & & \\
$n$-Heptane/ethanol flame & & \\
$n$-Heptane (mol\%) & 4.91 & 4.81 \\
Argon (mol\%) & 64.97 & 64.99 \\
Oxygen in $n$-heptane/oxygenate blend & 2.7 & 3.4 \\
(wt\%) & & \\
\hline
\end{tabular}

particulate matter and PAH emissions from in-use lightduty gasoline vehicles. $\mathrm{PM}_{10}$ emission rates were reduced considerably by the use of oxygenated fuel in FTP driving cycle at $35^{\circ} \mathrm{F}$. The total PAH emission rates of the nonoxygenated fuel were higher than those from the oxygenated fuel by an average factor of 1.55. However, the distribution of PAH compounds was not significantly different for the two fuels. The total PAH emission rate was dominated by the relatively large naphthalene and methylnaphthalene emissions.

In this study, we report the species mole fraction and temperature profiles in premixed, laminar, fuel-rich (equivalence ratio of 1.97) flames of $n$-heptane/oxygen/argon and $n$-heptane/oxygenate/oxygen/argon. Oxygenates tested were MTBE, methanol, and ethanol. Since the oxygen

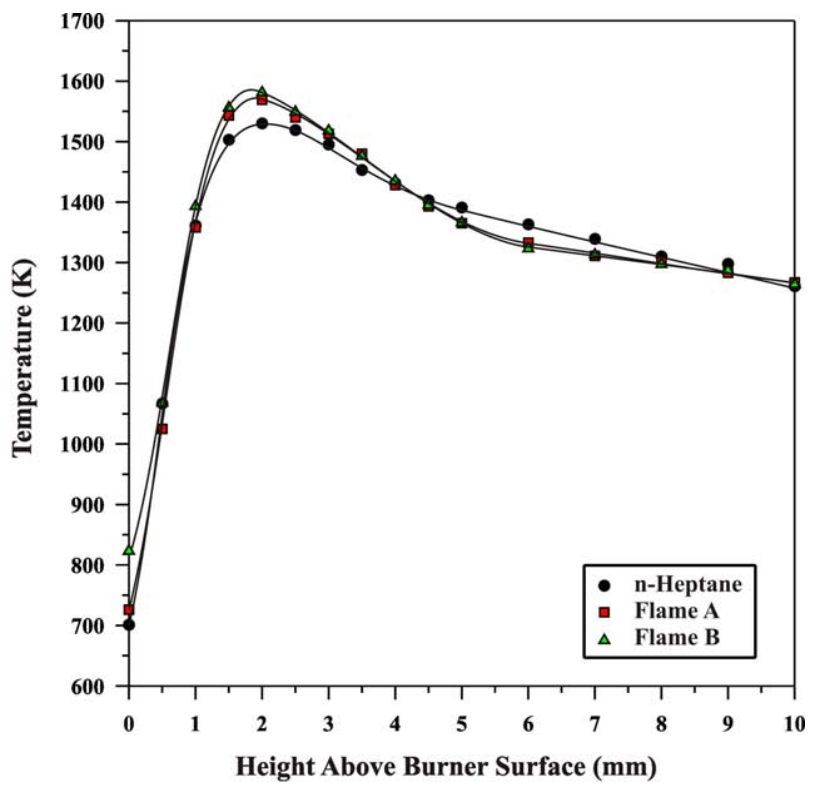

Fig. 1. Flame temperatures of $n$-heptane and MTBE flames. 


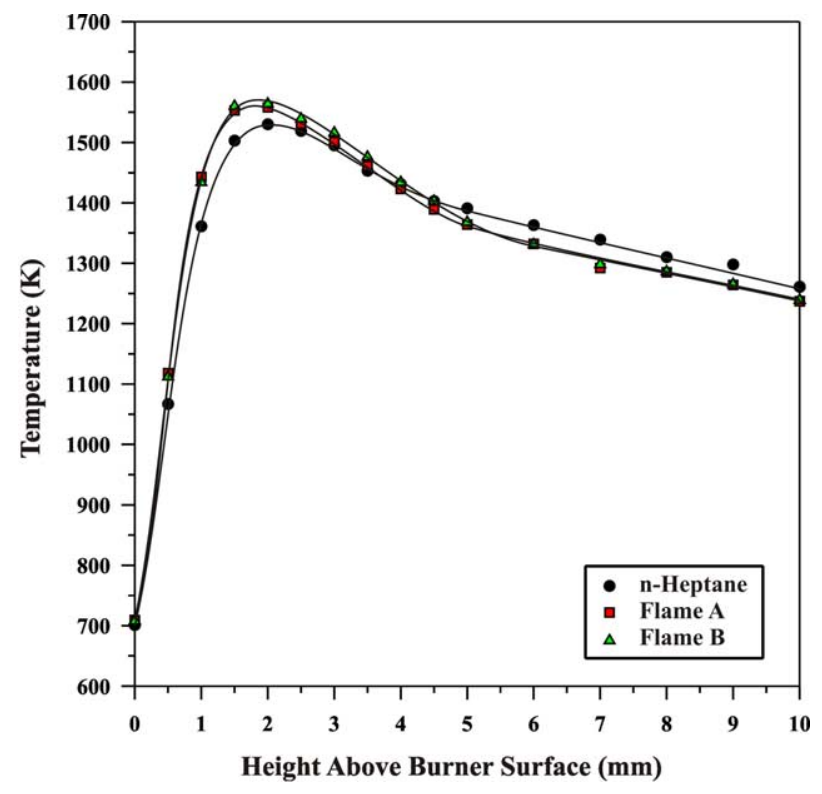

Fig. 2. Flame temperatures of $n$-heptane and methanol flames.

concentration in fuel blends is more appropriate parameter in determining the effects of oxygenate concentration on species mole fractions, two different conditions (i.e. 2.7 and $3.4 \mathrm{wt} \%$ oxygen in $n$-heptane/oxygenate mixture) have been investigated.

\section{Experimental}

The experimental setup used in this study has been described elsewhere [12,15] therefore, only a brief description will be given here. Atmospheric pressure, laminar, premixed, flat-flames of $n-\mathrm{C}_{7} \mathrm{H}_{16} / \mathrm{O}_{2} / \mathrm{Ar}$ and $n-\mathrm{C}_{7} \mathrm{H}_{16}$ l

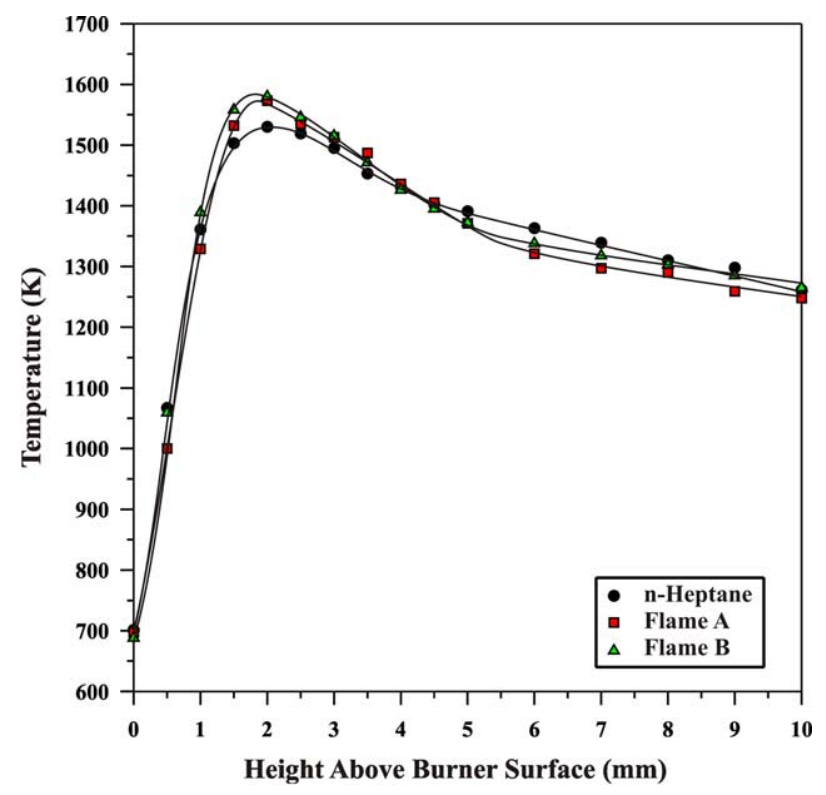

Fig. 3. Flame temperatures of $n$-heptane and ethanol flames.

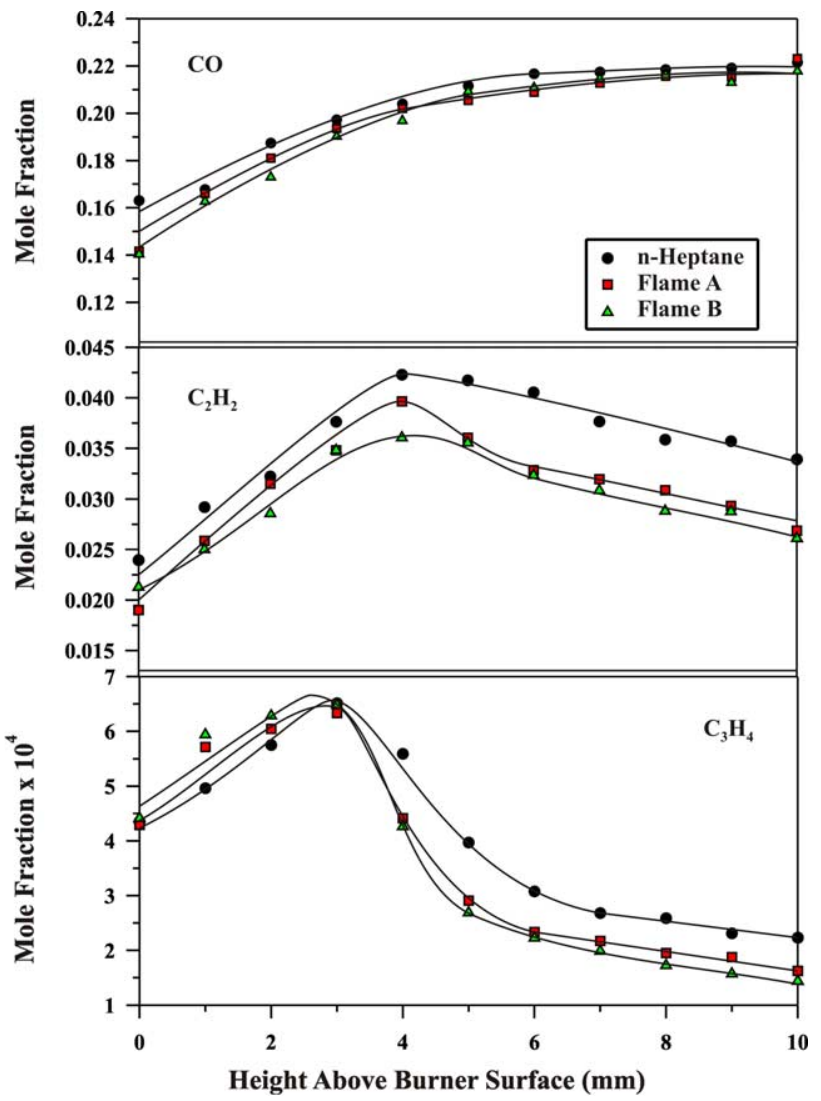

Fig. 4. Mole fraction profiles of $\mathrm{CO}, \mathrm{C}_{2} \mathrm{H}_{2}$, and $\mathrm{C}_{3} \mathrm{H}_{4}$ in $n$-heptane and MTBE flames.

oxygenate $/ \mathrm{O}_{2} / \mathrm{Ar}$ were stabilized over a $50 \mathrm{~mm}$ diameter porous, bronze burner. Argon was also used as shield gas to protect the flames from surrounding air. Oxygen (99.99\%) and argon (99\%) were obtained from Airco Welding Supply (Pomona, CA). Liquid fuel and oxygenates were acquired from the following vendors: $n$-heptane $(99 \%)$ and MTBE (HPLC grade) from Sigma Aldrich, methanol (99.9\%) from Fisher Scientific, and ethanol (HPLC grade) from Spectrum Quality Products. The flow rates of oxygen and argon were controlled by calibrated mass flow controllers (Model 247C, MKS). Two high precision syringe pumps (Isco Model 260D with Series D Pump Controller) were used to introduce the fuel and oxygenate into preheated mixtures of argon-oxygen stream at $150{ }^{\circ} \mathrm{C}$. The syringe pumps had flow rate resolution of $1 \mu \mathrm{l} / \mathrm{min}$ and flow rate accuracy of \pm $0.5 \%$. The argon shield gas was also heated to the temperature of reactant mixture to prevent condensation. Temperatures at different locations of the fuel delivery system were monitored and kept constant by a multichannel temperature read-out and proportional temperature controllers (Omega Engineering, Inc.).

The flame samples were withdrawn with an air heated quartz micro-probe at a temperature of about $300{ }^{\circ} \mathrm{C}$. Samples were then transferred through heated, glass-lined, stainless steel sampling line to a GC/MS system (HP 5890 Series II/5972) for analysis. The sampling probe and transfer 


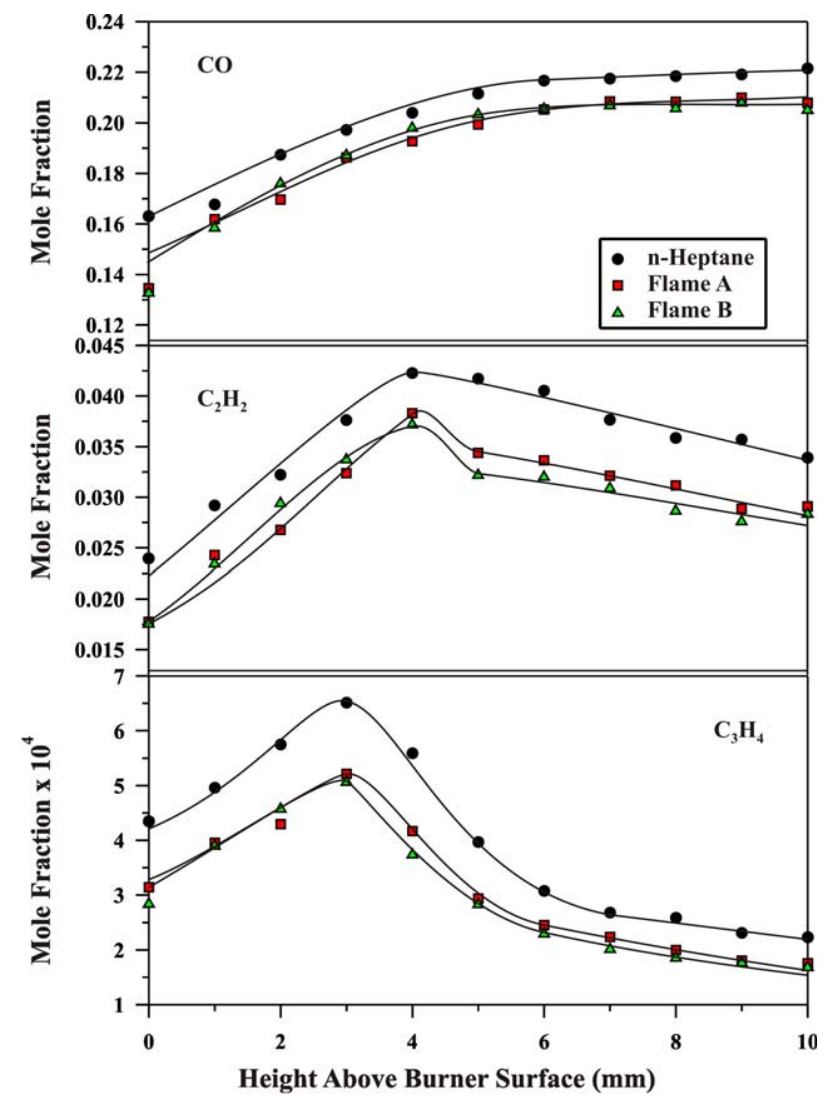

Fig. 5. Mole fraction profiles of $\mathrm{CO}, \mathrm{C}_{2} \mathrm{H}_{2}$, and $\mathrm{C}_{3} \mathrm{H}_{4}$ in $n$-heptane and methanol flames.

line was checked for possible catalytic activity by passing unburned gas mixture with known composition at room temperature and $300{ }^{\circ} \mathrm{C}$. We have not observed any catalytic activities within the sampling system. In addition, the possibility of production of low concentration unsubstituted and substituted aromatic species in sampling probe was investigated earlier in fuel-rich hydrocarbon flames using chemical kinetic modeling [24,25]. These modeling investigations indicated that, although it is kinetically possible, contributions of reactions in sampling probe to the measured concentrations of species should be minor.

Quantifications of species were done either directly using calibration standards (Matheson Gas, Sigma Aldrich) or by the use of ionization cross-section method [26]. The accuracy of the latter method has been reported to be within a factor of two [24]. We estimated an accuracy of about $\pm 15 \%$ for the mole fractions of species determined by direct calibration. The flame temperatures were measured using rapid insertion technique with a silicon oxide-coated Pt-13\% Rh/Pt, $0.075 \mathrm{~mm}$ thermocouple $[12,15]$.

The concentration and temperature profiles were generated by moving the burner assembly vertically up or down with respect to fixed position of thermocouple or quartz sampling micro-probe. The positional accuracy associated with these measurements was estimated to be $\pm 0.2 \mathrm{~mm}$.

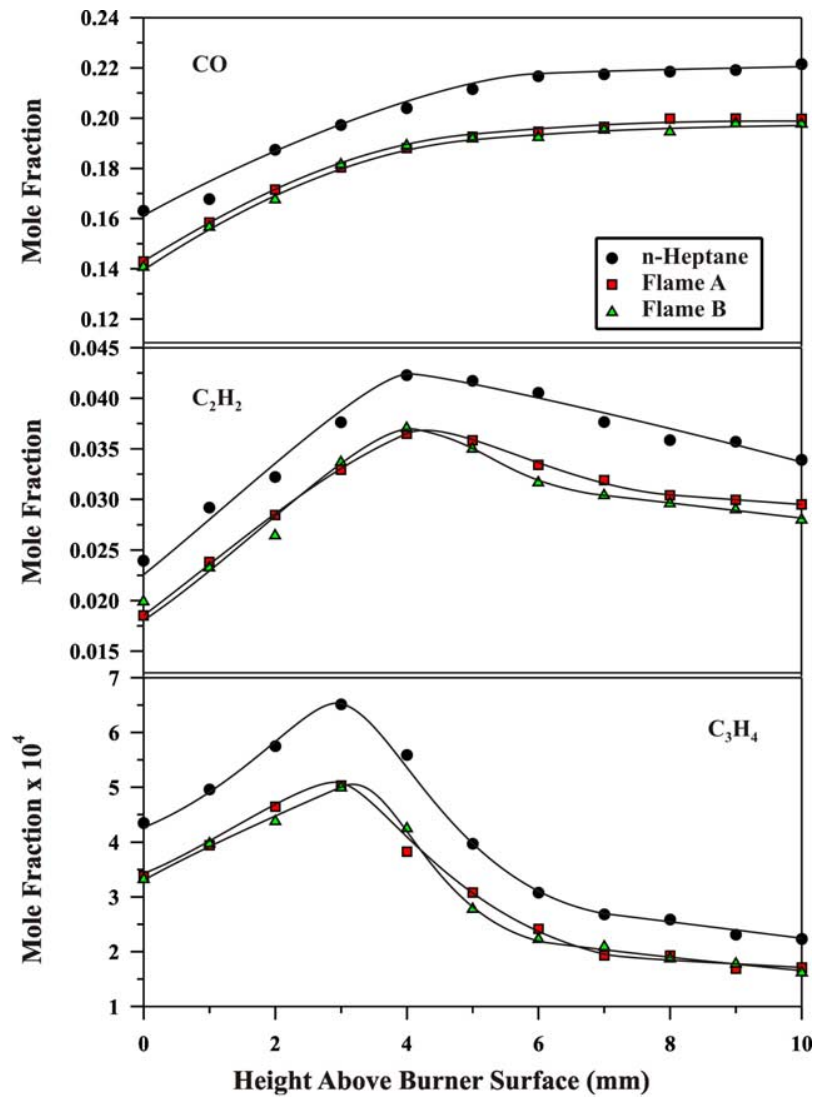

Fig. 6. Mole fraction profiles of $\mathrm{CO}, \mathrm{C}_{2} \mathrm{H}_{2}$, and $\mathrm{C}_{3} \mathrm{H}_{4}$ in $n$-heptane and ethanol flames.

\section{Results and discussion}

The experimental conditions studied in atmospheric pressure, premixed $n$-heptane/oxygenate/oxygen/argon flames at an equivalence ratio of 1.97 are listed in Table 1. In this table, flame-A and flame-B represent the flames containing 2.7 and $3.4 \mathrm{wt} \%$ oxygen in $n$-heptane/ oxygenate mixtures, respectively. The neat heptane flame was also considered as a reference flame to compare with oxygenate containing flames. $n$-Heptane and argon mole percentages in the reference flame were 5.33 and 64.97, respectively. In all the flames, argon dilution was kept at about $65 \%$.

The temperature profiles for the $n$-heptane and $n$ heptane/oxygenate flames are shown in Figs. 1-3. The data points represent experimental results and solid lines represent trends in all the figures presented here. The temperature profiles correspond to direct thermocouple readings and were not corrected for radiation losses. There are numerous methods to correct the raw thermocouple data for use in kinetic modeling [27]. These methods are based on a mathematical model that uses radiative heat losses, balanced with convective heat transfer to the thermocouple surface. In sooting flames, particles will deposit on the thermocouple junction and increase both its emissivity and diameter. Since these parameters are sensitive and uncertain 


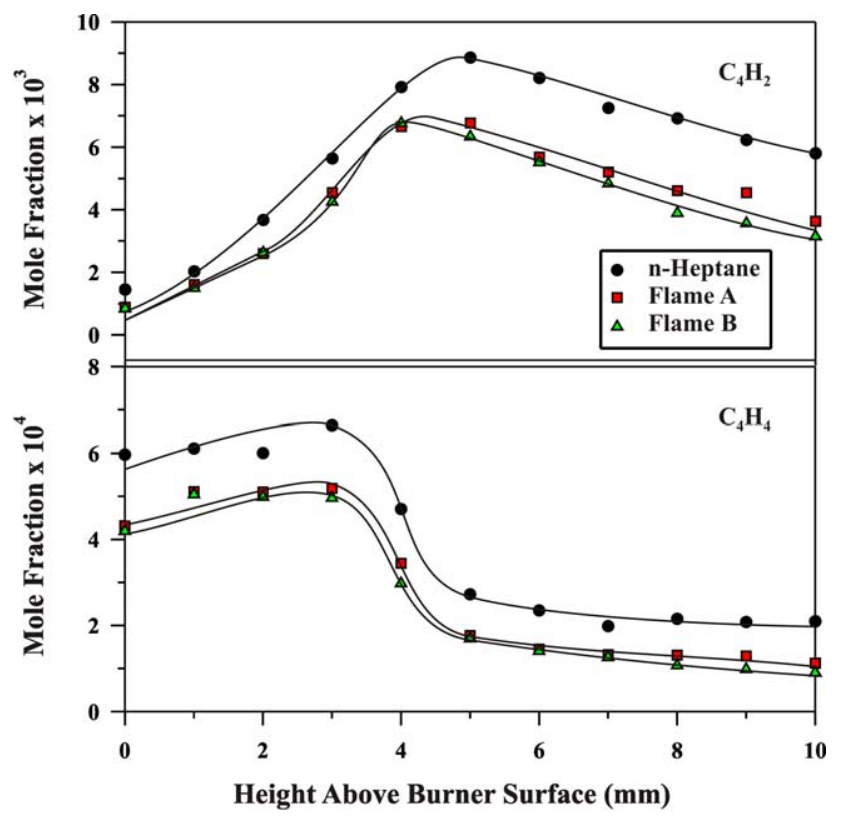

Fig. 7. Mole fraction profiles of $\mathrm{C}_{4} \mathrm{H}_{2}$ and $\mathrm{C}_{4} \mathrm{H}_{4}$ in $n$-heptane and MTBE flames.

parameters, and required in radiation loss corrections, we decided to leave this correction process to the readers to use their favorite methods of radiative correction. The maximum flame temperature was $1530 \mathrm{~K}$ for the neat $n$-heptane flame. The corresponding temperatures for flame-A and flame-B were 1569 and $1581 \mathrm{~K}$ in MTBE flames (Fig. 1), 1558 and $1564 \mathrm{~K}$ in methanol flames (Fig. 2), and 1573 and $1580 \mathrm{~K}$ in ethanol flames (Fig. 3), respectively. The peak temperatures were obtained at $2 \mathrm{~mm}$ above the burner surface for all the flames investigated. In general, the addition of oxygenate increased the maximum flame

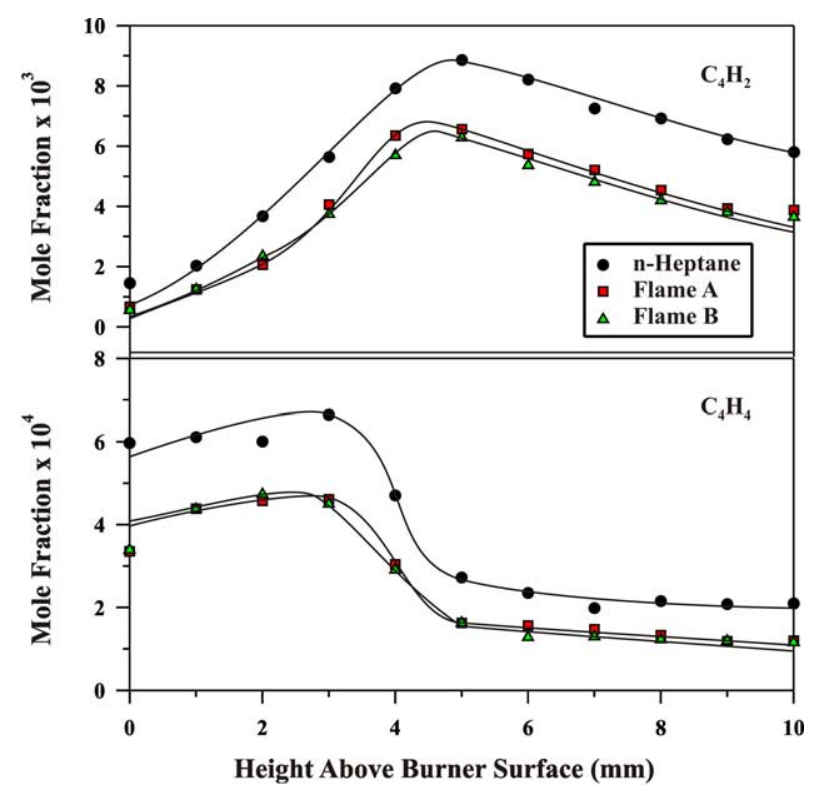

Fig. 8. Mole fraction profiles of $\mathrm{C}_{4} \mathrm{H}_{2}$ and $\mathrm{C}_{4} \mathrm{H}_{4}$ in $n$-heptane and methanol flames.

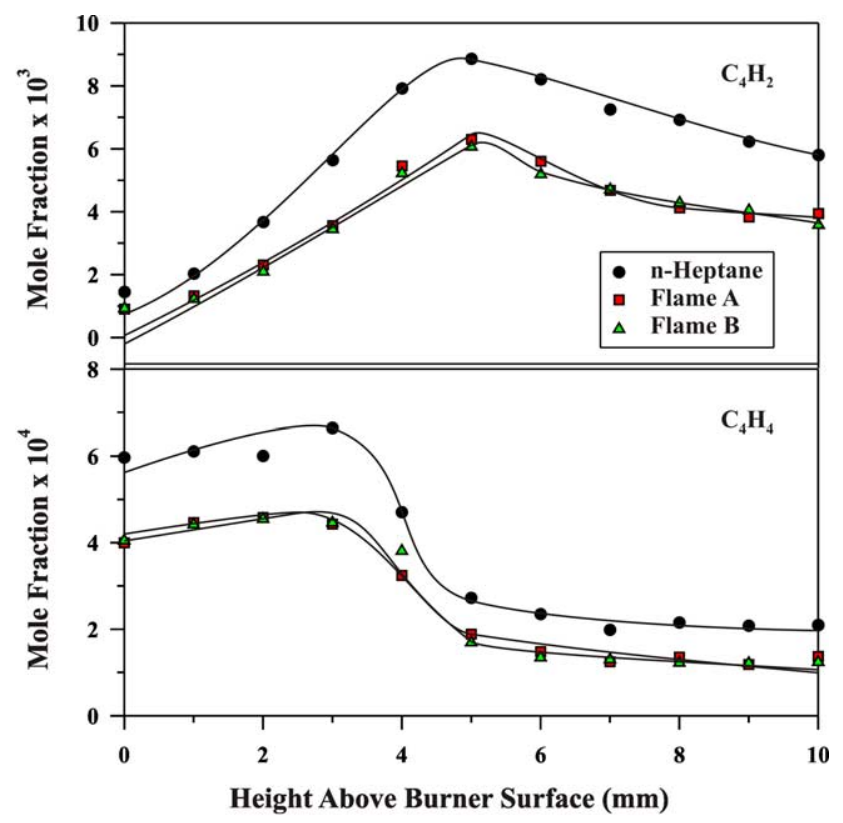

Fig. 9. Mole fraction profiles of $\mathrm{C}_{4} \mathrm{H}_{2}$ and $\mathrm{C}_{4} \mathrm{H}_{4}$ in $n$-heptane and ethanol flames.

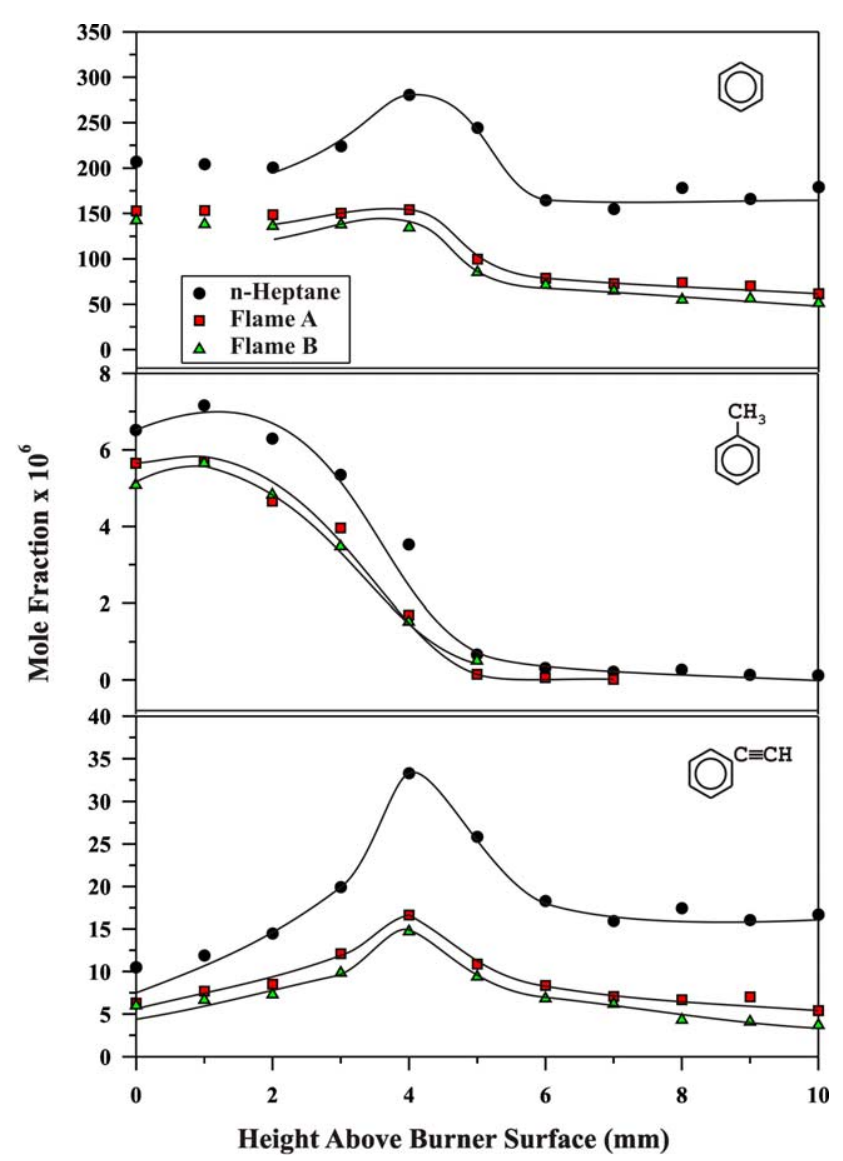

Fig. 10. Mole fraction profiles of benzene, toluene, and phenylacetylene in $n$-heptane and MTBE flames. 


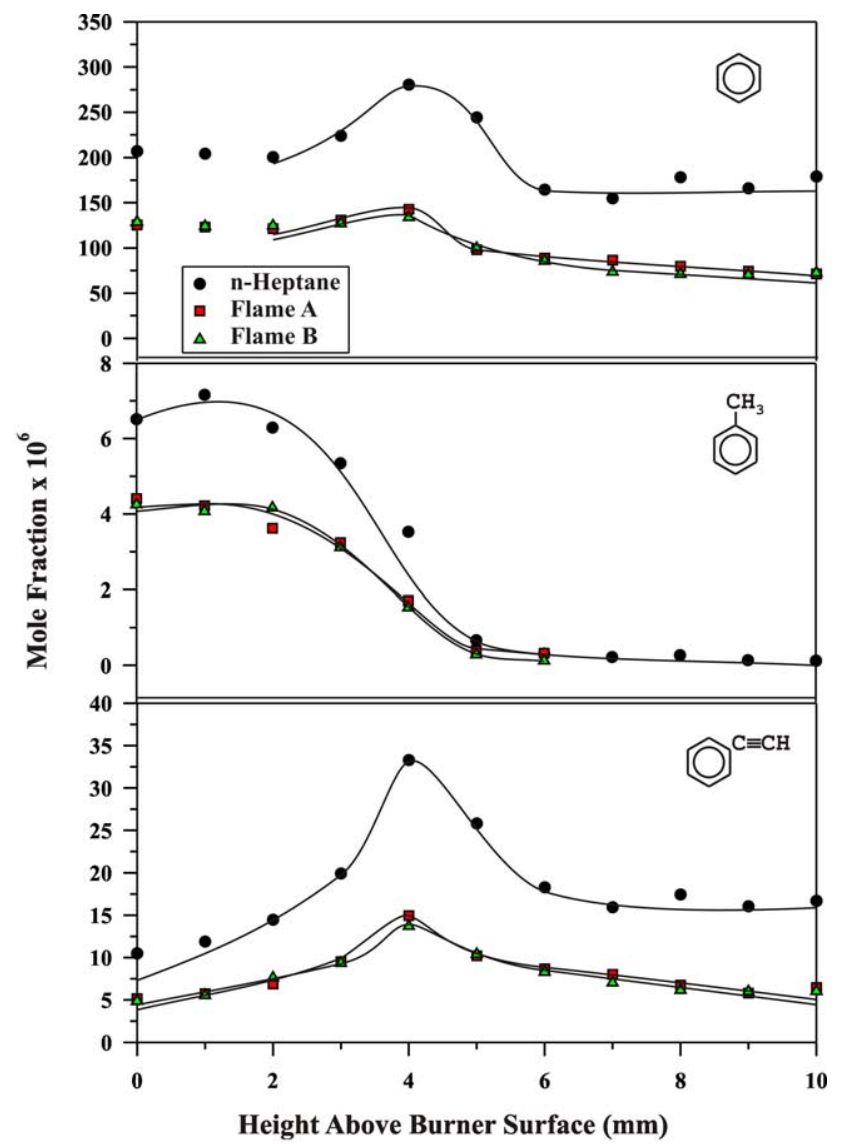

Fig. 11. Mole fraction profiles of benzene, toluene, and phenylacetylene in $n$-heptane and methanol flames.

temperature and the highest temperatures were obtained for flame-B. A maximum flame temperature of about $1600 \mathrm{~K}$ has been reported for the premixed $n$-heptane flame at an equivalence ratio of 1.9 , which is slightly higher than our temperature measurements because their flame was leaner [8].

Mole fraction profiles of the stable species are given in Figs. 4-15. As can be seen from these figures, for each species the shape of the profiles was similar in all flames. We used a quartz micro-probe with an orifice diameter of about $0.200 \mathrm{~mm}$ in flame sampling. Therefore, the mole fraction profiles reported here represent values that are spatially averaged over 2-3 orifice diameters. In addition, data within a few millimeters above the burner surface should be considered questionable due to the possible sampling probe-burner surface interactions.

The mole fraction profiles of $\mathrm{CO}$, acetylene $\left(\mathrm{C}_{2} \mathrm{H}_{2}\right)$, and 1,2-propadiene/1-propyne $\left(\mathrm{C}_{3} \mathrm{H}_{4}\right)$, are presented in Figs. 4-6 for the neat $n$-heptane and oxygenate containing flames. As expected, $\mathrm{CO}$ was the major combustion product and its mole fraction increased steadily with distance from the burner surface, and leveled off at about $9 \mathrm{~mm}$. With respect to the concentration in neat $n$-heptane flame, the reductions in $\mathrm{CO}$ mole fractions in flame-A and flame-B were about $1-4$ and $1-8 \%$ in MTBE flames, 3-9 and 3-7\%

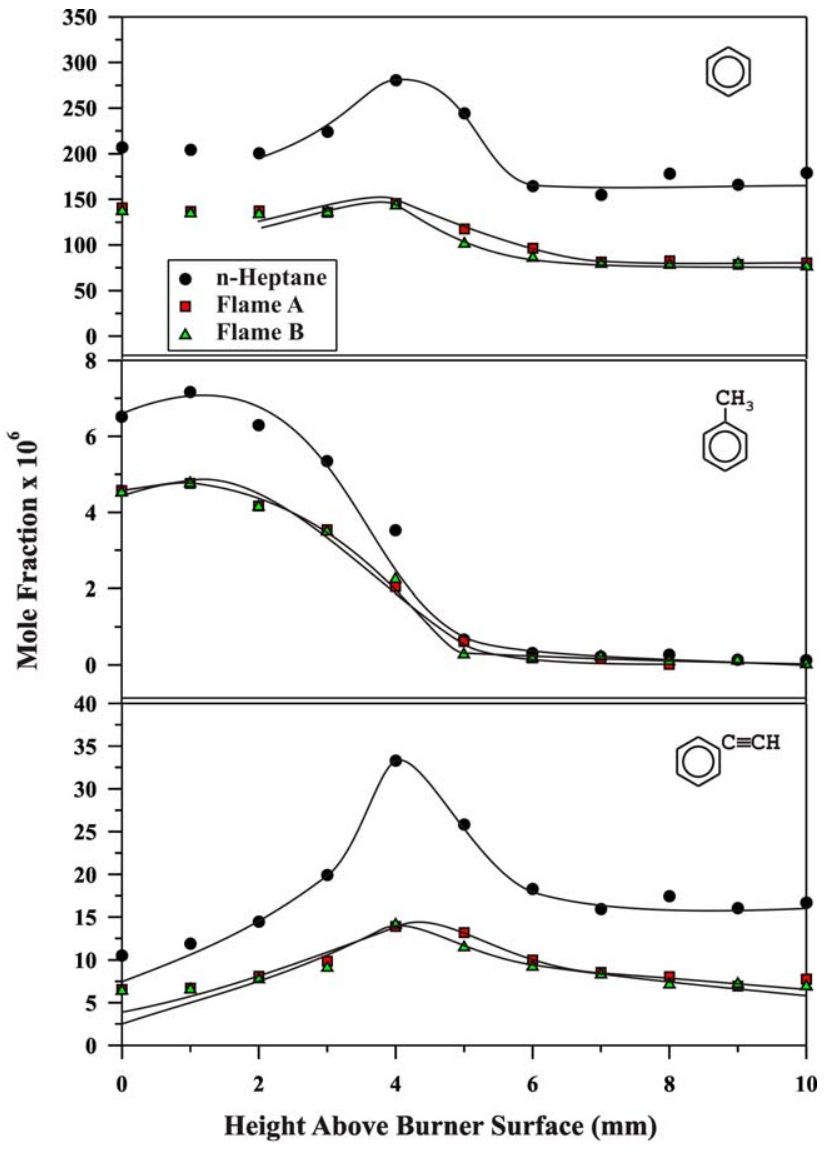

Fig. 12. Mole fraction profiles of benzene, toluene, and phenylacetylene in $n$-heptane and ethanol flames.

in methanol flames, and 5-10 and 7-11\% in ethanol flames, respectively. The percent reductions in ethanol flames were slightly higher than those obtained for other two oxygenates. An increase in oxygenate concentration decreased the $\mathrm{CO}$ mole fractions up to $4 \%$. Maximum mole fractions of $\mathrm{C}_{3} \mathrm{H}_{4}$ were about the same (i.e. $\sim 6.5 \times 10^{-4}$ ) in neat $n$-heptane and MTBE flames (for both flame-A and flame$B)$, which were higher than the levels in methanol and ethanol flames (i.e. $\sim 5 \times 10^{-4}$ ).

Concentration profiles of diacetylene $\left(\mathrm{C}_{4} \mathrm{H}_{2}\right)$, and vinylacetylene $\left(\mathrm{C}_{4} \mathrm{H}_{4}\right)$ are shown in Figs. 7-9. $\mathrm{C}_{2} \mathrm{H}_{2}$ and $\mathrm{C}_{4} \mathrm{H}_{2}$ were the primary hydrocarbon species detected. The peak mole fractions of $\mathrm{C}_{2} \mathrm{H}_{2}, \mathrm{C}_{3} \mathrm{H}_{4}, \mathrm{C}_{4} \mathrm{H}_{2}$ and $\mathrm{C}_{4} \mathrm{H}_{4}$ were at or above $3 \mathrm{~mm}$ from the burner surface. These species penetrated into the post-flame zone, indicating their role in $\mathrm{PAH}$ formation chemistry. The maximum mole fractions of $\mathrm{C}_{2} \mathrm{H}_{2}$ and $\mathrm{C}_{4} \mathrm{H}_{2}$ in flame-B were $3.6 \times 10^{-2}$ and $6.8 \times 10^{-3}$ in MTBE flames, $3.7 \times 10^{-2}$ and $6.3 \times 10^{-3}$ in methanol flames, and $3.7 \times 10^{-2}$ and $6.1 \times 10^{-3}$ in ethanol flames, respectively. Except $\mathrm{C}_{4} \mathrm{H}_{2}$, the concentration levels of lowmolecular-weight hydrocarbon species (i.e. $\mathrm{C}_{2} \mathrm{H}_{2}, \mathrm{C}_{3} \mathrm{H}_{4}$, and $\mathrm{C}_{4} \mathrm{H}_{4}$ ) in the reference flame were in agreement with those reported earlier for a premixed, fuel-rich $n$-heptane flame [8]. The differences in $\mathrm{C}_{4} \mathrm{H}_{2}$ concentrations are about a factor of 10-30. The reason for this disagreement is not 


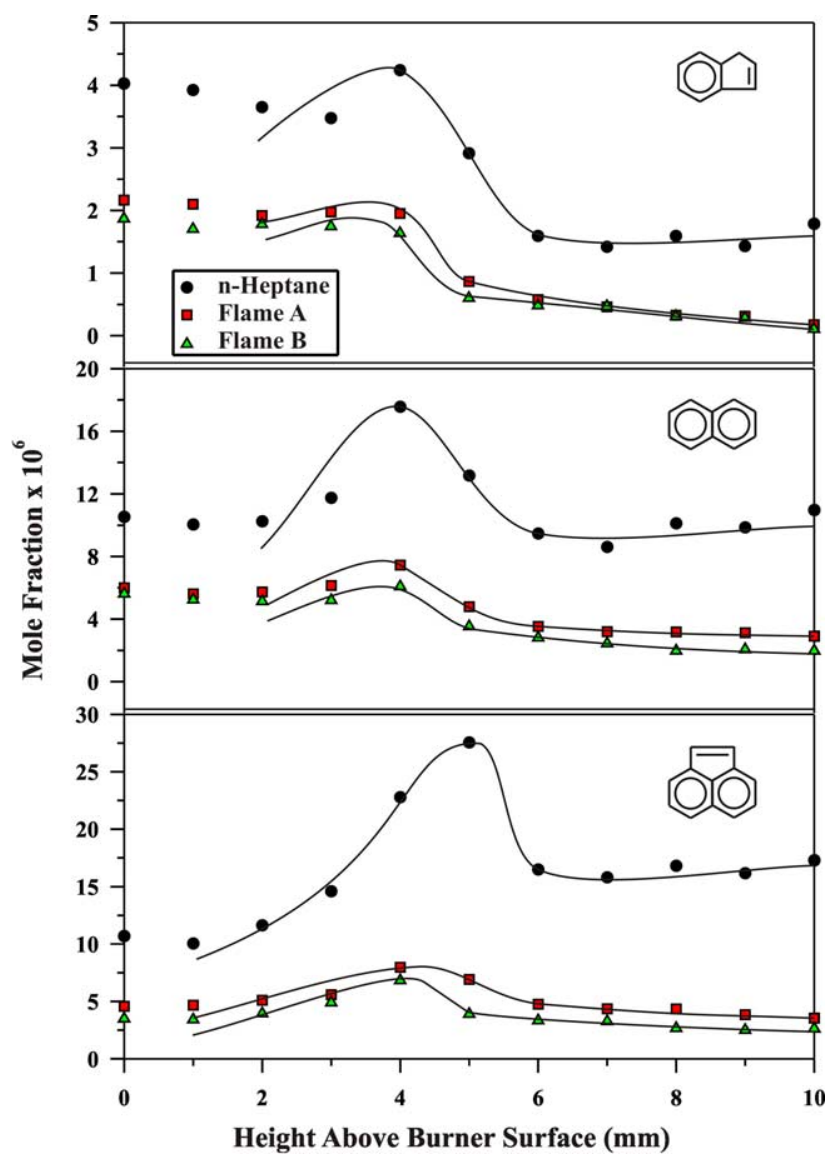

Fig. 13. Mole fraction profiles of indene, naphthalene, and acenaphthylene in $n$-heptane and MTBE flames.

clear but it may be due to the different reference species used for the calculations of the ionization cross-section.

An increase in oxygenate concentration from 2.7 to $3.4 \mathrm{wt} \%$ oxygen in $n$-heptane/oxygenate mixture has slightly decreased the mole fractions of low-molecularweight reaction products (Figs. 4-9). In most cases, the reductions were less than $10 \%$.

The previous studies have shown that at high temperatures, $n$-heptane consumption occurs by the thermal decomposition via $\mathrm{C}-\mathrm{C}$ bond rupture and $\mathrm{H}$-atom abstraction by a number of radical species (e.g. $\mathrm{H}, \mathrm{O}, \mathrm{OH}, \mathrm{HO}_{2}$, $\mathrm{CH}_{3}$ ) [4,28-30]. The $\mathrm{H}$-atom abstraction reactions form four isomers of $n$-heptyl radical $\left(\mathrm{C}_{7} \mathrm{H}_{15}\right)$. These radicals are consumed primarily through the $\beta$-scission of a $\mathrm{C}-\mathrm{C}$ bond. However, the oxidation mechanism of alcohols involves the production of oxygenated and non-oxygenated intermediates directly from the fuel by dehydration or dehydrogenation [31]. The experimental and modeling studies have indicated that methanol and ethanol oxidations are initiated mostly by reactions with the $\mathrm{OH}$ and $\mathrm{H}$ radicals $[32,33]$. The addition of methanol and ethanol into fuel blends acts as traps for $\mathrm{H}$ and $\mathrm{OH}$, and therefore reduces the $n$-heptane oxidation. In the case of MTBE, the major oxidation pathway is a unimolecular decomposition, producing isobutene and methanol [14,31]. Isobutene is less reactive

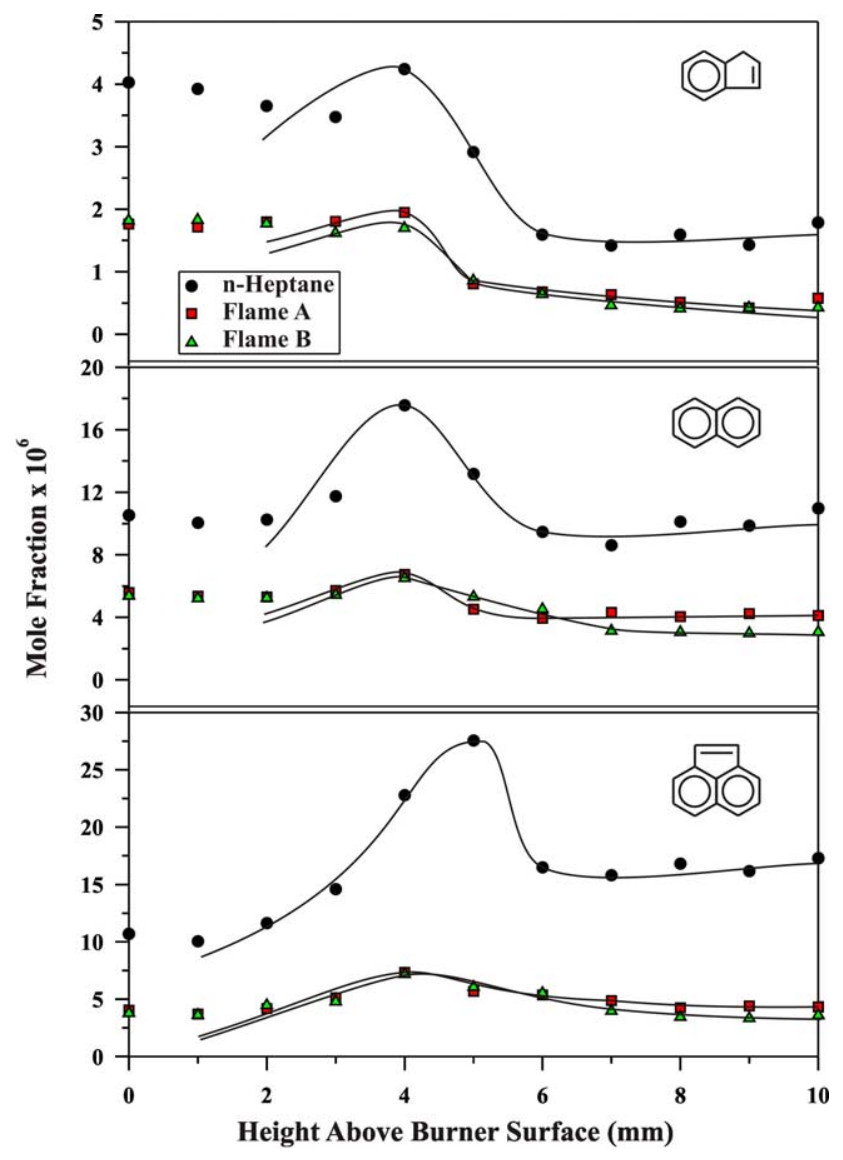

Fig. 14. Mole fraction profiles of indene, naphthalene, and acenaphthylene in $n$-heptane and methanol flames.

than hydrocarbons formed by the thermal decomposition of $n$-heptane and $n$-heptyl radicals. As a result, the production of less reactive intermediate isobutene reduces the concentrations of small hydrocarbons.

The mole fraction profiles of single-ring aromatics and PAH species are shown in Figs. 10-15. These figures indicate that the addition of oxygenates significantly reduced the mole fractions of aromatics and PAH species up to about $75 \%$ with respect to the levels in neat $n$-heptane flame, which has also been reported for a premixed $n$-heptane flame at an equivalence ratio of 2.10 [15]. Benzene was the most abundant aromatic species in all the flames investigated. The maximum mole fractions of benzene in flame-A and flame-B were about 154 and $137 \mathrm{ppm}$ in MTBE flames, 143 and $134 \mathrm{ppm}$ in methanol flames, and 145 and $143 \mathrm{ppm}$ in ethanol flames, respectively (Figs. 10-12). An increase in oxygenate concentration reduced the benzene mole fraction less than $20 \%$ in most cases. There are several mechanisms proposed for the formation of first aromatic ring in flames of non-aromatic fuels. Frenklach and Wang [34] suggested that the vinyl addition to acetylene is the first step in this reaction mechanism. Vinylacetylene is formed at high temperatures, and followed by acetylene addition to $n-\mathrm{C}_{4} \mathrm{H}_{3}$ radical formed by the $\mathrm{H}$-abstraction 


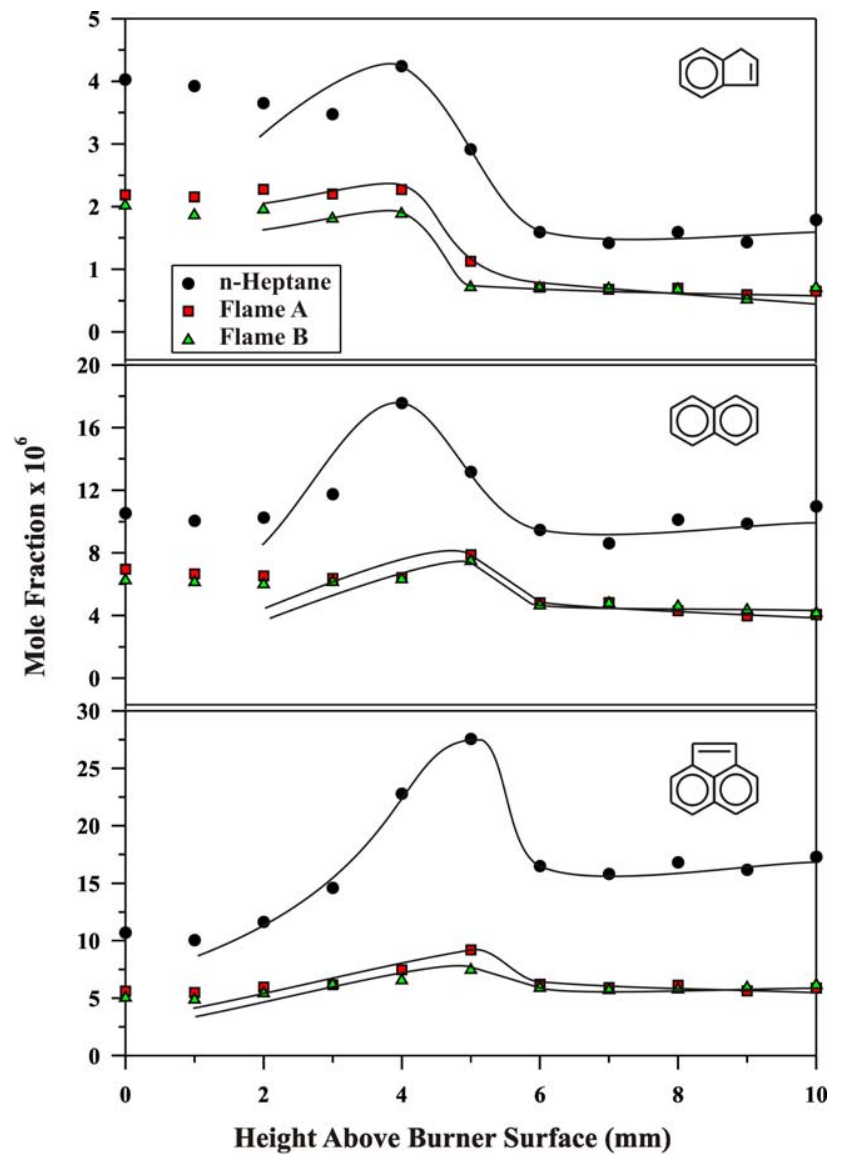

Fig. 15. Mole fraction profiles of indene, naphthalene, and acenaphthylene in $n$-heptane and ethanol flames.

from the vinylacetylene. The combination of propargyl radicals also produces benzene or phenyl [35]. Recent studies have shown that the benzene formation occurs through both the $C_{3}$ and $C_{4}$ chains $[29,36]$.

With the exception of toluene, the mole fraction profiles of aromatic and PAH species peaked at or above $4 \mathrm{~mm}$ from the burner surface (Figs. 10-15). Toluene showed an earlier maximum, which indicates a rapid consumption at shorter distances above the burner surface than other aromatics (Figs. 10-12). A similar profile for toluene has also been reported for the combustion of $n$-heptane [15,36] and other hydrocarbon fuels [37].

Naphthalene and acenaphthylene were the primary PAH species with maximum mole fractions in flame-B of about 6.1 and $6.8 \mathrm{ppm}$ in MTBE flames, 6.5 and $7.2 \mathrm{ppm}$ in methanol flames, and 7.5 and $7.4 \mathrm{ppm}$ in ethanol flames, respectively (Figs. 13-15). Up to $40 \%$ reductions were obtained in mole fractions of these PAH species with an increase in oxygenate concentration in fuel blends. For some aromatic species, the percent reductions in MTBE flames were slightly higher than those for other two oxygenate containing flames.

The small unsaturated hydrocarbons are known to be responsible for the formation and growth of aromatic and $\mathrm{PAH}$ species in flames. The decrease in mole fractions of these precursors by the addition of oxygenates can be related to the observed reductions in concentrations of aromatics and $\mathrm{PAH}$.

\section{Conclusions}

The effects of oxygenate concentration on species mole fractions have been investigated in premixed, atmospheric pressure $n$-heptane/oxygenate/oxygen/argon flames at oxygen weight percents of 2.7 and 3.4 in $n$-heptane/oxygenate mixtures. The initial $n$-heptane concentrations were reduced by the addition of oxygenates into fuel blends. Oxygenate additives affect the flame chemistry by reducing the radical pool and/or producing less reactive reaction intermediates. The maximum flame temperatures increased by the oxygenate addition. An increase in oxygen weight percent in fuel blends decreased the concentrations of $\mathrm{CO}$ (up to about 4\%), small hydrocarbons (up to about 10\%), aromatics (up to about 20\%) and PAH species (up to about $40 \%$ ). The significant reductions were obtained for aromatics and PAH.

\section{References}

[1] International Energy Outlook. Report DOE/EIA-0484. Energy Information Administration; 2003.

[2] Burcat A. Int Symp Shock Tubes Waves 1981;13:826.

[3] Ciezki H, Adomeit G. Int Symp Shock Tubes Waves 1987;16:481.

[4] Chakir A, Bellimam M, Boettner JC, Cathonnet M. Int J Chem Kinet 1992;24:385.

[5] Dagaut P, Reuillon M, Cathonnet M. Combust Flame 1995;101:132.

[6] Westmoreland PR, Howard JB, Longwell JP. Second annual progress report—center for health effects of fossil fuel utilization. MIT; 1980.

[7] Doute C, Delfau JL, Akrich R, Vovelle C. Combust Sci Tech 1997; 124:249.

[8] Bakali AE, Delfau J-L, Vovelle C. Combust Sci Tech 1998;140:69.

[9] Ingemarsson AT, Pedersen JR, Olsson JO. J Phys Chem A 1999;103: 8222.

[10] Hamins A, Seshadri K. Combust Flame 1987;68:295.

[11] Peterca L, Marconi F. Combust Flame 1989;78:308.

[12] Inal F, Senkan SM. Combust Flame 2002;131:16.

[13] Levinson GS. Combust Flame 1965;9:63.

[14] Dagaut P, Koch R, Cathonnet M. Combust Sci Tech 1997;122:345.

[15] Inal F, Senkan SM. Combust Sci Tech 2002;174:1.

[16] Bishop GA, Morris JA, Stedman DH. Environ Sci Technol 2001;35: 2874.

[17] Magnusson R, Nilsson C, Anderson B. Environ Sci Technol 2002;36: 1656.

[18] Osman MM, Matar MS, Koreish S. Fuel Sci Technol Int 1993;11: 1331.

[19] Poulopoulos S, Philippopoulos C. Atmos Environ 2000;34:4781.

[20] Cadle SH, Mulawa P, Groblicki P, Laroo C, Ragazzi RA, Nelson K, Gallagher G, Zielinska B. Environ Sci Technol 2001;35:26.

[21] Zervas E, Montagne X, Lahaye J. Environ Sci Technol 2001;35:2746.

[22] Zervas E, Montagne X, Lahaye J. Environ Sci Technol 2002;36:2414.

[23] Zervas E, Montagne X, Lahaye J. Environ Sci Technol 2003;37:3232.

[24] Castaldi MJ, Vincitore AM, Senkan SM. Combust Sci Technol 1995; 107:1.

[25] Olten N, Senkan SM. Combust Flame 1999;118:500. 
[26] Fitch WL, Sauter AD. Anal Chem 1983;55:832.

[27] Bradley D, Matthews KJ. J Mech Eng Sci 1968;10:299.

[28] Coats CM, Williams A. Proc Combust Inst 1979;17:611.

[29] Lindstedt RP, Maurice LQ. Combust Sci Technol 1995;107:317.

[30] Held TJ, Marchese AJ, Dryer FL. Combust Sci Technol 1997;123: 107.

[31] Norton TS, Dryer FL. Proc Combust Inst 1990;23:179.

[32] Alzueta MU, Bilbao R, Finestra M. Energy Fuels 2001;15:724.
[33] Alzueta MU, Hernandez JM. Energy Fuels 2002;16:166.

[34] Frenklach M, Wang H. Detailed mechanism and modeling of soot particle formation. In: Bockhorn $\mathrm{H}$, editor. Soot formation in combustion. Berlin: Springer; 1994. p. 165-92.

[35] Miller JA, Melius CF. Combust Flame 1992;91:21.

[36] McEnally CS, Ciuparu DM, Pfefferle LD. Combust Flame 2003;134: 339.

[37] Melton TR, Inal F, Senkan SM. Combust Flame 2000;121:671. 